\section{Acknowledgments.}

Financial support. No financial support was provided relevant to this article.

Conflicts of interest. All authors report no conflicts of interest relevant to this article.

\section{References}

1. Dellit TH, Owens RC, McGowan JE, et al. Infectious Diseases Society of America and the Society for Healthcare Epidemiology of America guidelines for developing an institutional program to enhance antimicrobial stewardship. Clin Infect Dis 2007;44:159-177.

2. Core elements of hospital antibiotic stewardship programs. Centers for Disease Control and Prevention (CDC) website. https://www.cdc. gov/antibiotic-use/core-elements/hospital.html. Published 2020. Accessed November 16, 2020.

3. Stevens MP, Patel PK, Nori P. Involving antimicrobial stewardship programs in COVID-19 response efforts: all hands on deck. Infect Control Hosp Epidemiol 2020;41:744-745.

4. Mazdeyasna H, Nori P, Patel P. et al. Antimicrobial stewardship at the core of COVID-19 response efforts: implications for sustaining and building programs. Curr Infect Dis Rep 2020;22(9):23.

5. Ahmad H, Guo Y, Yaghdjian V, et al. Hospital emergency response to novel influenza A (H1N1) pandemic in a large New York City hospital: an opportunity for antimicrobial stewardship. Hosp Pharm 2012;47:532-537.
6. Crommelin DJA, Volkin DB, Hoogendoorn KH, Lubiniecki AS, Jiskoot W. The science is there: key considerations for stabilizing viral vector-based COVID-19 vaccines. J Pharm Sci 2020. doi: 10.1016/j.xphs.2020.11.015

7. ACIP presentation slides: December 2020 meeting, December 1, 2020. Coronavirus disease (COVID-19) vaccines. Centers for Disease Control and Prevention (CDC) website. https:/www.cdc.gov/vaccines/acip/meetings/ slides-2020-12.html. Published 2020. Accessed December 2, 2020.

8. Biasio LR, Bonaccorsi G, Lorini C, Pecorelli S. Assessing COVID-19 vaccine literacy: a preliminary online survey. Hum Vaccin Immunother 2020. doi: 10.1080/21645515.2020.1829315.

9. Lazarus JV, Ratzan SC, Palayew A, et al. A global survey of potential acceptance of a COVID-19 vaccine. Nat Med 2020. doi: 10.1038/s41591020-1124-9.

10. Facts about COVID-19 vaccines. Centers for Disease Control and Prevention (CDC) website. https://www.cdc.gov/coronavirus/2019-ncov/ vaccines/vaccine-benefits/facts.html?CDC_AA_refVal=https\%3A\%2F\% 2Fwww.cdc.gov\%2Fcoronavirus\%2F2019-ncov\%2Fvaccines\%2Fabout-vaccines \%2Fvaccine-myths.html. Published 2020. Accessed December 3, 2020.

11. Antimicrobial stewardship requirements for hospitals. The Joint Commission website. https://www.jointcommission.org/-/media/deprecated-unorganized/ imported-assets/tjc/system-folders/assetmanager/adhoc_hap_abx_r3_201608 22pdf.pdf? db=web\&hash=10A09E9017D5576E6E101FFB789C8336. Published 2020. Accessed December 2, 2020.

12. Patel PK, Nori P, Stevens MP. Antimicrobial stewardship and bamlanivimab: opportunities for outpatient preauthorization? Infect Control Hosp Epidemiol 2020. doi: 10.1017/ice.2020.1343.

\title{
"Would you like a flu shot with your order?"-A coronavirus disease 2019 (COVID-19) pandemic drive-through response to address delayed pediatric immunization in Detroit, Michigan
}

\author{
Eric J. McGrath $\mathrm{MD}^{1}$ (1) , Donia Dalal MPH${ }^{2}$, Lynn Smitherman $\mathrm{MD}^{1}$, Sharon Marshall MD ${ }^{1}$, Christopher Youngman MD $^{1}$, \\ Charles J. Barone MD $^{3}$, Herman Gray MD ${ }^{1}$, Najibah Rehman MD $^{2}$ and Elizabeth Secord MD ${ }^{1}$ \\ ${ }^{1}$ Department of Pediatrics, Wayne State University School of Medicine, Detroit, Michigan, ${ }^{2}$ Detroit Health Department, Detroit, Michigan and ${ }^{3}$ Department of \\ Pediatrics, Henry Ford Hospital, Detroit, Michigan
}

To the Editor-Since the coronavirus disease 2019 (COVID-19) pandemic and associated "shelter in place" orders in the spring of 2020 , numerous children in the United States, ${ }^{1}$ but especially in Michigan, ${ }^{2}$ have not received the recommended immunizations. Furthermore, baseline Michigan vaccination rates have been low. Here, we describe an effort to address this public health crisis within the COVID-19 crisis.

A "drive-through" immunization fair ${ }^{3-6}$ was held Saturday, October 10,2020 , in which parents and their children (aged 6 weeks to 18 years) stayed in their vehicles and all participants $>2$ years old wore required facemasks. The Wayne Pediatrics (WP) clinical group, affiliated with Wayne State University (WSU) School of Medicine (SOM), collaborated with the Detroit Health Department (DHD) to offer the event. Parents were encouraged to call the DHD to schedule a drive-through

\footnotetext{
Author for correspondence: Eric J. McGrath, E-mail: emcgrath@med.wayne.edu Cite this article: McGrath EJ, et al. (2022). "Would you like a flu shot with your order?"-A coronavirus disease 2019 (COVID-19) pandemic drive-through response to address delayed pediatric immunization in Detroit, Michigan. Infection Control \& Hospital Epidemiology, 43: 265-266, https://doi.org/10.1017/ice.2020.1410
}

appointment before the day of the event, but patients who showed up to the event without an appointment were also seen. Before the event, local families were informed about the event through advertising with bulk mailings of postcards, by social media, by e-mail alerts to community partners, and by other widespread marketing publicity.

Routine vaccines from the 2020 pediatric schedule ${ }^{7}$ were offered to participants due for immunization or requesting influenza vaccine. Immunizations were supplied by the DHD. The WP clinic-building parking lot was used for one-way traffic flow (Fig. 1). Henry Ford Pediatrics donated their pediatric mobile vehicle and professional driver for the event. Older children could receive vaccines in their deltoid or shoulder though their vehicle window, and the mobile unit was used for privacy for infants and very young children vaccinates in the upper thigh.

The DHD dedicated staff members included an immunization coordinator, 2 nurses, 2 patient navigators, and 2 registration staff. The WP clinic staff volunteers included a nurse, 4 medical assistants, the clinical manager, a clinical supervisor, 2 medical secretaries, and 6 physicians. Each completed a 4.5-hour shift for the 12-hour event. 
Fig. 1. The COVID-19 pandemic drive-through immunization event traffic flow diagram.

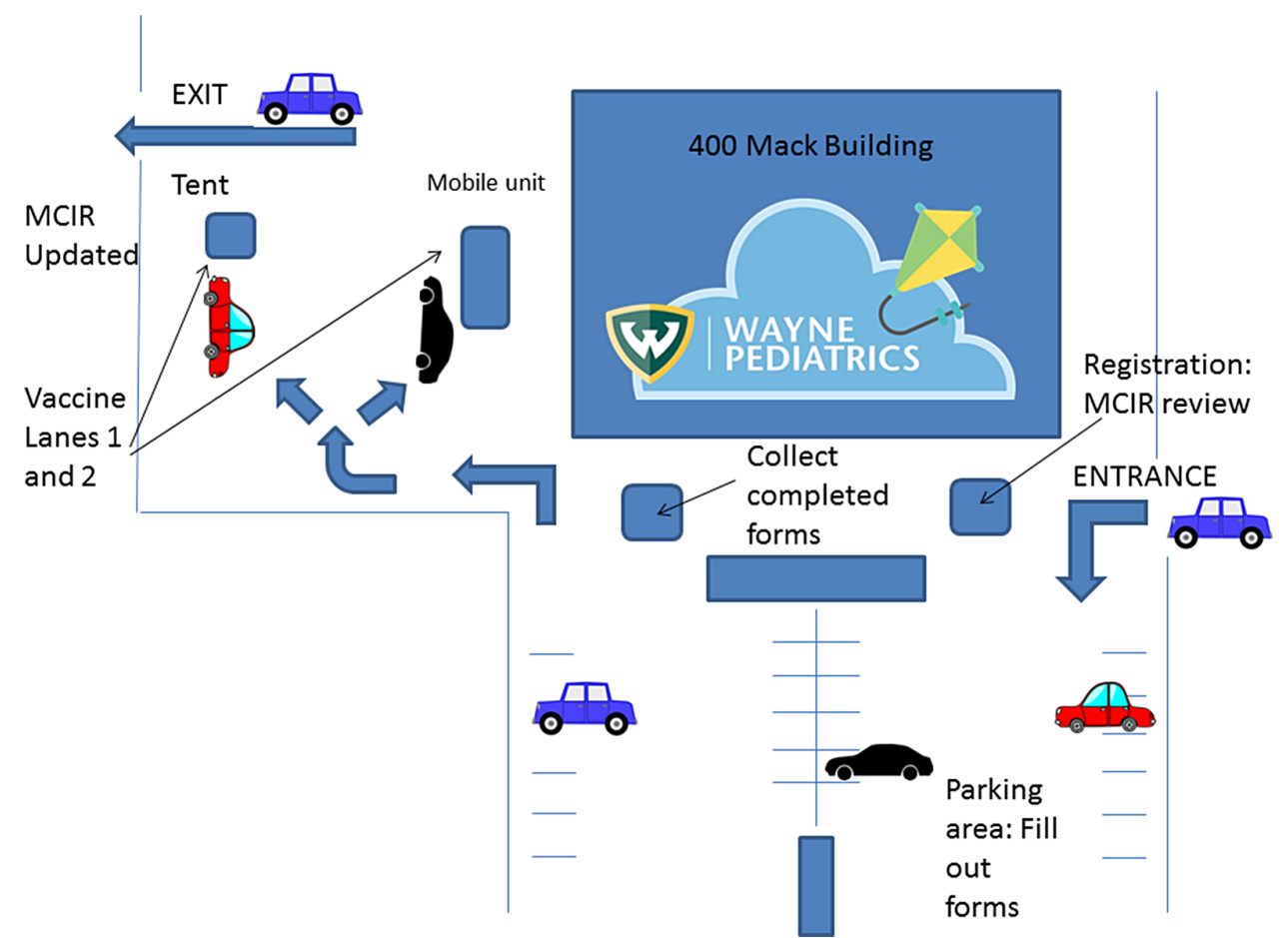

Furthermore, 19 WSU SOM second-year medical students trained in PPE donning and doffing and immunization administration practices by in-person demonstration 2 days prior to the event; each completed a 2-hour volunteer shift during the event. A special events manager from WSU was present the entire day, and 3 WSU police officers helped with vehicle traffic.

At registration, the parent received a pen (to keep), intake paperwork, and a plastic (sanitizable) clipboard to complete required documentation. Parent identification and insurance cards were verified by DHD staff. The Michigan Care Improvement Registry (MCIR) vaccine record database was accessed for each participant with on-site, mobile computers and printers. The DHD staff reviewed the MCIR record to assess required or past-due immunizations. All participants remained in their vehicle while volunteer clinical staff and medical students picked up the completed forms. Finally, families were guided toward 1 of 2 drive-through lanes and were vaccinated by DHD nurses. The MCIR was updated in real-time, was printed, and was then given to the parent.

All volunteer medical and clinical staff with direct patient contact donned the following PPE: mask or respirator, face shield or goggles, gown (when vaccinating a participant), and gloves. Volunteers clearing an initial temperature check and paper-based COVID-19 symptom evaluation form then received ongoing temperature checks every 2 hours. Hand sanitizer was readily available for hand hygiene. All volunteer staff used clinic restrooms that were professionally cleaned after the event.

This event took place during the COVID-19 pandemic, with an emphasis on enhanced infection prevention methods for families and volunteers. During the event, 40 participants were successfully immunized.
Acknowledgments. The authors thank Tina Lyles from WSU Special Events for her support with the event.

Financial support. No financial support was provided relevant to this article.

Conflicts of interest. All authors report no conflicts of interest relevant to this article.

\section{References}

1. Santoli JM, Lindley MC, DeSilva MB, et al. Effects of the COVID-19 pandemic on routine pediatric vaccine ordering and administration-United States, 2020. Morb Mortal Wkly Rep 2020;69:591-593.

2. Bramer CA, Kimmins LM, Swanson R, et al. Decline in child vaccination coverage during the COVID-19 pandemic-Michigan Care Improvement Registry, May 2016-May 2020. Morb Mortal Wkly Rep 2020;69:630-631.

3. Banks L, Vanderjagt A, Crandall C. The view through the window: characterizing participants in a drive-through influenza vaccination clinic. Disaster Med Public Health Prep 2014;8:243-246.

4. Banks LL, Crandall C, Esquibel L. Throughput times for adults and children during two drive-through influenza vaccination clinics. Disaster Med Public Health Prep 2013;7:175-181.

5. Rega P, Bork C, Chen Y, Woodson D, Hogue P, Batten S. Using an H1N1 vaccination drive-through to introduce healthcare students and their faculty to disaster medicine. Am J Disaster Med 2010;5:129-136.

6. Swanson L. Drive thru, prevent flu. CMAJ. 2003;169:1197.

7. US Department of Health and Human Services. Recommended child and adolescent immunization schedule for ages 18 years or younger, United States, 2020. Centers for Disease Control and Prevention website. https:// www.cdc.gov/vaccines/schedules/hcp/imz/child-adolescent.html. Published 2020. Updated February 3, 2020. Accessed December 14, 2020. 